\title{
Risk factors for road traffic accidents among drivers of public institutions in Ibadan, Nigeria
}

\author{
Charles O. Bekibele 1 , Olafunmilayo I. Fawole², Afolabi E. Bamgboye², Lola V Adekunle², Ronke Ajav ${ }^{3}$ and \\ Aderonke M. Baiyeroju ${ }^{1}$
}

1. Department of Ophthalmology, 2. Department of Epidemiology, Medical Statistics, and Environmental Health, College of Medicine. 3. University Staff Clinic Services, University of Ibadan, Nigeria.

*Corresponding author: Cob150@yahoo.com; Fax234 2 2413545; Phone:2348033233564

\section{SUMMARY}

\begin{abstract}
Recent studies have shown an increase in the rate of road traffic accident (RTA). Identifying the risk factors for this problem may provide a clue to possible effective intervention. This study aimed to determine the prevalence and risk factors for self reported RTA among drivers of educational institutions and make suggestions to promote safer driving. A cross sectional population study of motor vehicle drivers from the College of Medicine, University of Ibadan and University College Hospital (UCH) Ibadan was undertaken between December 2003 and January 2004. The study comprised of 99 motor vehicle drivers. 67 (67.7\%) were from the College of Medicine, and $32(32.3 \%)$ from the UCH. Response rate was $97.1 \%$. All were males, aged 38 to 60 years, mean $50.1 \pm(\mathrm{SD}=\mathbf{4 . 8}$ years). The prevalence of self reported $\mathrm{RTA}$ was $\mathbf{1 6 . 2 \%}$. The cause of road traffic accidents included, mechanical fault $(50 \%)$, bad road $(12.5 \%)$. RTA prevalence was higher among older drivers $(\mathrm{OR}=1.7,95 \% \mathrm{CI}=0.5-5.9 ; \mathrm{P}>0,05)$, drivers who had part time jobs (Odds ratio $2.6,95 \%$ CI $1.1-6.3 ; \mathrm{X}^{2}=4.5, \mathrm{P}=0.03$ ), and drivers with visual impairment $\left(O R=1.6,95 \% C I=0-9, X^{2} 0.49, P>0.05\right)$. The prevalence of RTA was lower amongst drivers who did not take alcohol, cola nut and other CNS stimulants while driving (OR 0.9, 95\% CI=0.3-2.3, $P>0.05)$. Regular maintenance of official vehicles and examination of drivers' eyes are recommended. Drivers should be discouraged from drugs and part jobs so as to ensure that they have enough time to rest and therefore prevent fatigue related RTA.
\end{abstract}

[Afr J Health Sci. 2007; 14:137-142]

\section{Introduction}

Recent studies have shown an increase in the rate of road traffic accidents (RTA) in many developing and developed countries [1]. This is attributed in part to urbanization, industrialization, as well as the increase in the number of motor vehicles on the roads. In Nigeria, many lives are lost daily through motor vehicle accidents [2]. Asogwa [1] in 1978 analysed an eight-year period RTA data in Nigeria obtained from the office of the Inspector General of Police. He observed a rising trend in the incidence of RTA over the study period. Comparison of the rates of RTA in Nigeria with those of developed countries (such as United Kingdom, Sweden and Australia) as well as other developing countries (such as Zambia, Tanzania, Uganda and Kenya) showed that Nigeria had the highest mortality and morbidity rates due to RTA.

Analysis of accident victims by age and sex showed victims are predominantly young adult males with an age range of $26-30$ years $[2,3]$. The causes of RTA were multi factorial and were attributed to: recklessness and negligence of the driver $(61.3 \%)$, mechanical defects in vehicle
(8.4\%), careless crossing of the road by pedestrians (12.7\%), bad road and other less important causes accounted for $(17.6 \%)$. Analysis of the condition of drivers involved in RTA showed that use of drugs such as alcohol, kola nut and Indian hemp at time of accident was an important factor in the occurrence of RTA (although the use was often denied) [3]. Over $12 \%$ of RTAs were under influence of caffeine in kola nut, 7.74\% alcohol, and 1.62 Indian hemp [4]. The role of poor sight in accident causation has also been well documented $[5,6,7]$. Nwosu in his study of 719 motor vehicle drivers in the Oyo State Government Service in Nigeria, found the prevalence of subnormal vision to be $3.1 \%$ [8]. A statistically significant association was documented between road traffic accidents and subnormal visual acuity. Owsley et al [9] examined the effect of cataract on driving and found that drivers with cataract were 2.5 times more likely to have had a history of involvement in accident compared to their counterparts without cataract. This they attributed to visual impairment, which is associated with cataract. Another study in Canada which examined the association between 
driver's medical condition and crash severity, observed that the crashes of truck drivers with binocular visual problems and bus drivers with hypertension were more serious than those of healthy drivers [10]. There is paucity of data on the prevalence and risk factors for RTA by drivers in public institutions. This study therefore aims at determining the prevalence and risk factors for RTA among drivers of the College of Medicine University of Ibadan and the University College Hospital (UCH) so as to make suggestions for safer driving.

\section{Materials and Methods}

This was a cross sectional study, carried out at the Eye Clinic, of the University College Hospital Ibadan over a 2 months period between December 2003 and January 2004. Subjects for the study were all (102) motor vehicle drivers out of a total staff population of 3505 employed by the College of Medicine, University of Ibadan (810) and the University College Hospital $(2,696)$, Ibadan. Both institutions are located within the same premises in Ibadan but are under different management structure. The management of the University of Ibadan is subject to the Federal Ministry of Education while the management of the hospital is subject to the Federal Ministry of Health.

Ethical approval was obtained from the $\mathrm{UI} / \mathrm{UCH}$ joint institutional review committee before the commencement of the study. Subjects were recruited through the respective heads of department, the university health service, University of Ibadan and the University College Hospital, Ibadan. Every participant was given a voluntary consent form after thorough explanation of the procedure involved. All drivers consented to participate in the study but eventually 3 of them did not show up. Subjects were interviewed using a standard semi-structured self-administered questionnaire. The questionnaire was divided into five sections to ease administration. Section A asked questions on socio-demographic characteristics including age (names were excluded to ensure confidentiality), marital status, religion and level of education. Section B focused on driving experience and questions were asked about the number of years of active driving, year of commencement of driving occupation, and involvement in other part time jobs. Section C obtained ocular history. Questions were asked about the type of glasses worn while driving, duration of wearing eye glasses, current and previous eye complaints or diseases. Section D obtained RTA history by asking about the number of road traffic accidents sustained while driving, since commencement of the profession, and in the last 5 years. The cause of accident, association with poor sight, alcohol intake or other medications when RTA occurred, was also documented. Information about use of stimulants such as cola nut, bitter cola and other medications while driving was sought. Section E was reserved for eye examination. Eye examination was carried out by only the principal investigator (an ophthalmologist) and this eliminated inter observer error. These included measurement of visual acuity in both eyes and examination of the eyes with a torch-light, then a direct ophthalmoscope, slit lamp, and a single measurement of intraocular pressure using a Goldman applanation tonometer. Gonioscopy with a three-mirror gonioscopy lens was done only for subjects with elevated intraocular pressure and optic disc cupping suggestive of glaucoma. Objective refraction was done using a Keeler streak retinoscope followed by objective refraction to determine the presence of underlying refractive error and presbyopia. Colour vision was tested with the aid of an Ishihara colour vision chart. Peripheral and central perimetry was finally done using a Lister manual perimetry machine to identify the presence of field defects in the subjects.

The data generated was coded, entered into a personal computer using facilities in the Statistical Package for Social Sciences (SPSS) version 10.0. Frequency tables and proportions were used for data summarization and presentation of qualitative data. Means and standard deviations were used for quantitative data, while odds ratios were calculated as estimates of relative risk of suspected variables.

\section{Results}

A total of ninety-nine motor vehicle drivers were recruited into the study out of which $67(67.7 \%)$ came from the College of Medicine, while 32 $(32.3 \%)$ were from the $\mathrm{UCH}$. The response rate from the college of medicine drivers was $100 \%$ while that for UCH was $91.4 \%$. Three drivers in the employment of the $\mathrm{UCH}$ were not interviewed because they were out on fieldwork through out the duration of the study. The drivers were all males with age range of 38 to 60 years; mean 50.1 and standard deviation of 4.8 years. A sizeable majority $(97 \%)$ of the drivers were married while 3 were unmarried. Sixty $(60.6 \%)$ were Christians and 39 (39.4\%) were Moslems. Eighty-two (82.8\%) had primary six leaving certificate as highest level of education while $17(17.2 \%)$ had secondary education. All drivers had professional driving licence, with driving experience ranging from 5 years to 43 years, mean 27.94 years and standard deviation of 6.24 . Over $31.0 \%$ of the drivers were engaged in part time jobs to help supplement their income. The distribution of part time jobs engaged in by the drivers is as shown in Table 1 . 
Table 1: Type of part time jobs done by the drivers

\begin{tabular}{lcc}
\hline Part time job & Number of drivers & $\%$ \\
\hline Taxi driving & 5 & 5.1 \\
Electrician & 3 & 3.0 \\
Estate agent & 1 & 1.0 \\
Farming & 12 & 12.1 \\
Mechanic & 2 & 2.0 \\
Musician & 1 & 1.0 \\
Pastor & 2 & 2.0 \\
Tailor & 1 & 1.0 \\
Trading & 2 & 2.0 \\
Nil & 67 & 67.7 \\
Total & 99 & 100.0 \\
\hline
\end{tabular}

The prevalence of self reported RTA since they commenced driving, as an occupation was $16.2 \%$. Out of these only $11(11.1 \%)$ and $4(4 \%)$ had sustained road traffic accidents since employment by the establishments and in the last 5 years respectively. Majority of the accidents (47.8\%) were mild with no serious bodily injuries or damage to the vehicle. Twenty five percent and
$31.2 \%$ of the accidents were moderately serious or very serious with major injuries/mortality or damage to the vehicle. Most of the accidents $(87.5 \%)$ occurred during the day while only $12.5 \%$ occurred at night. Causes of road traffic accidents varied from mechanical fault $(50 \%)$ to bad road $(12.5 \%)$. Details of causes of road traffic accidents are as shown in Table 2.

Table 2: Causes of road traffic accidents sustained by the drivers

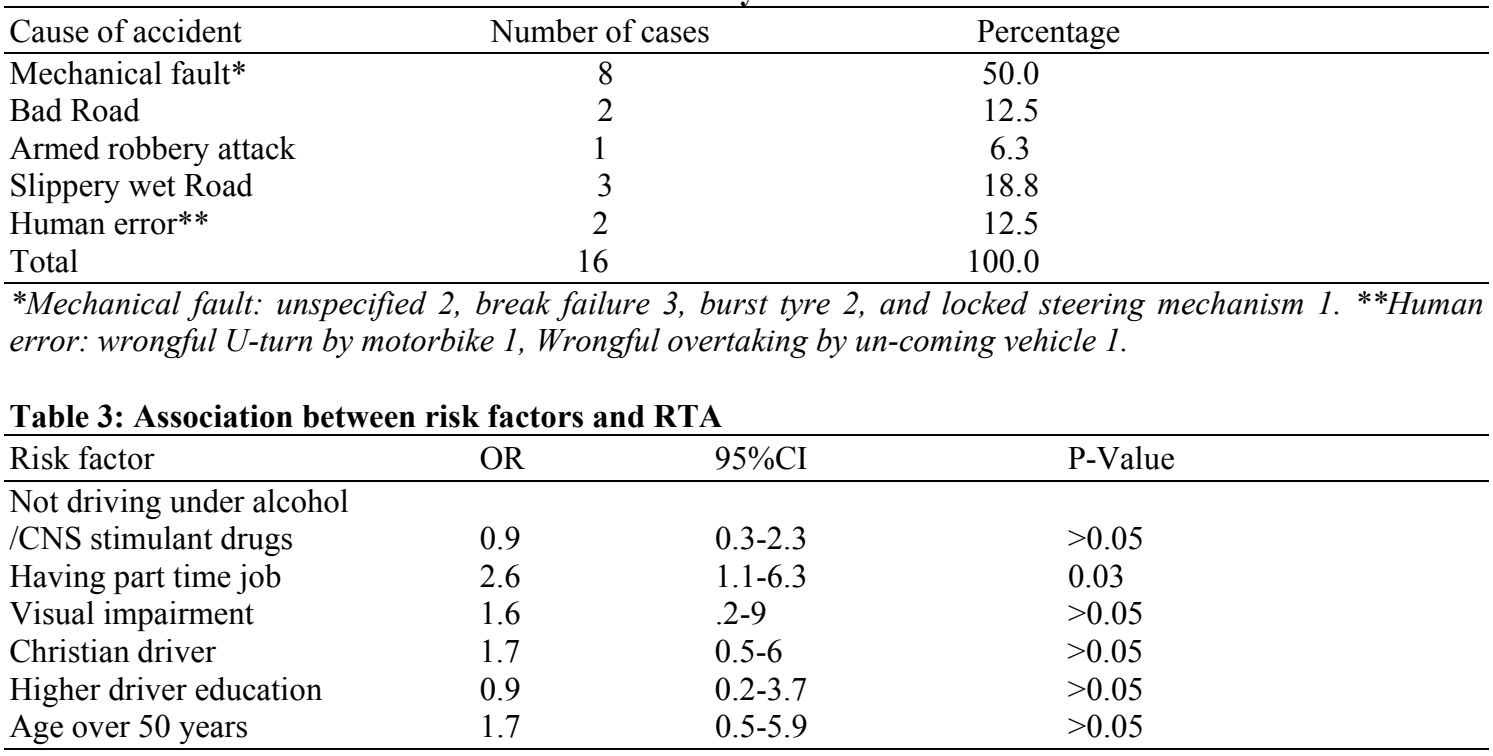

Examination of the effect of religion on accident prevalence among the drivers observed that $13.3 \%$ of Christian drivers as against $7.7 \%$ of Moslem drivers had RTA since employment by the College $\left(\mathrm{OR}=1.7, \quad 95 \% \mathrm{CI}=0.49-6 ; \quad \mathrm{X}^{2}=0.38, \mathrm{P}>0.05,\right)$. Level of education was found to have no significant effect on accident rates, with $11 \%$ of drivers having primary school education as against $12.5 \%$ with higher education levels having RTA
$(\mathrm{OR}=0.9, \quad 95 \% \quad \mathrm{CI}=0.2-3.7 ; \quad \mathrm{X} 2=0.8, \quad \mathrm{P}>0.05)$. RTA prevalence was observed to be higher among older drivers with $7.3 \%$ of drivers less than 50years of age as compared to $15.9 \%$ over 50 years of age having RTA, this risk persisted when consideration was made for the last 5 years alone with $1.8 \%$ of drivers less than 50years of age as against $6.8 \%$ over 50 years of age having RTA $(\mathrm{OR}=1.7$, $95 \% \mathrm{CI}=0.5-5.9 ; \mathrm{P}>0,05)$. 
Fig 1: Distribution of stimulants and alcohol use by the drivers

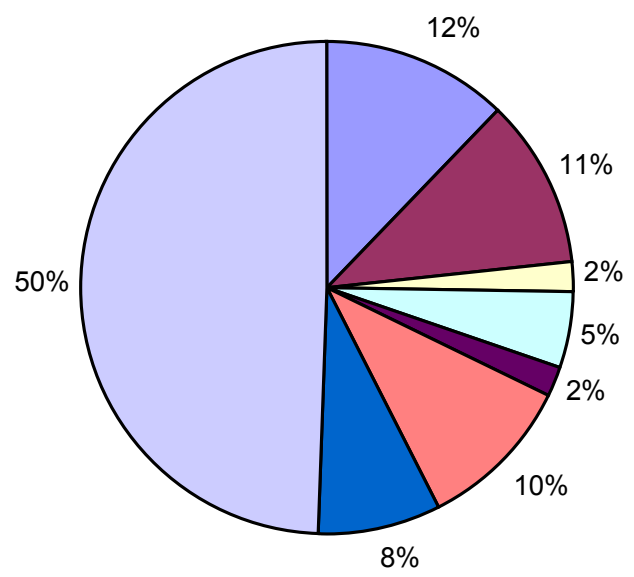

\begin{tabular}{|l|}
\hline$\square$ kolanut \\
$\square$ biter kola \\
$\square$ cigarette \\
$\square$ alcohol \\
$\square$ K,BK,Cig \\
$\square$ K,BK. \\
$\square$ K,BK,Alc \\
$\square$ nil \\
\hline
\end{tabular}

\section{$K=$ Kola nut, $B K=$ bitter Kola, Cig=Cigarette, Alc=alcohol}

Fifty $(50.5 \%)$ of the drivers admitted the use of alcohol, caffeine or nicotine containing drugs in different combinations while driving occasionally. Figure 1 shows the distribution of stimulants and other drugs used by the drivers. When the data was further analysed to see the effect of drugs on RTA rates among the drivers, it was observed that $15.7 \%$ of those who did not use drugs compared to $16.7 \%$ who used drugs while driving were involved in RTA (OR 0.9, 95\% CI 0.3-2.4, P >0.05). Not using drugs such as alcohol, kola nut and other stimulants therefore appeared to be protective, although this was not statistically significant. A statistically significant increased risk of RTA by drivers who had part time jobs compared to those without was however observed on examining the effect of part time job on RTA (Odds ratio 2.6, 95\% CI 1.1-6.3; $\mathrm{X}^{2}=4.5, \mathrm{P}=0.03$ ). Examination of the relationship between visual impairment and road traffic accident revealed that none of the drivers with optically correctable bilateral or having right- sided visual impairment was involved in an RTA. However $23.1 \%$ of the drivers classified as having 'unaided visual impairment' as against $15.1 \%$ of those with 'normal vision' were involved in RTA, $\left(\mathrm{OR}=1.5,95 \% \mathrm{CI}=0.5-4.6, \mathrm{X}^{2} 0.53, \mathrm{P}>0.05\right)$. Twenty five percent of the drivers with optically un-correctable visual impaired left eye compared with $15.8 \%$ with normal vision had RTA, $\left(\mathrm{OR}=1.6,95 \% \mathrm{CI}=0-9, \mathrm{X}^{2} \quad 0.49, \mathrm{P}>0.05\right)$. There was therefore an increased risk of RTA with visual impairment/ blindness among UCH/ College of Medicine, drivers but this risk was not statistically significant. Tables 3, shows a summary of the associations of possible risk factors and RTA.

\section{Discussion}

The accident rate of the drivers since their employment was $11.1 \%$. This was higher than the accident rate of $6.8 \%$ reported from a survey of Nigerian army drivers in Lagos [11]. The causes of RTA were similar except that poor vision was not reported by any of our drivers as a possible cause. An increased risk of RTA amongst visually impaired drivers was however observed in the analysis suggesting an important role for poor vision in accident causation despite its denial by the drivers studied. A study, which examined the association between visual impairment and RTA among 1,428 drivers seen at the accident and emergency department of a hospital in the United Arab Emirates, also identified visual impairment, careless driving and speed violations to be significant risk factors [12]. The importance of recklessness and negligence as opposed to mechanical fault in RTA causation was also noted in a study by Oyemade [2]. However $72 \%$ of the drivers involved in Oyemade's study were less than 30 years of age while $55 \%$ of the drivers from the United Emirates study were less than 40 years of age. These populations were much younger than those in our study (average age 50 years, with $1 \%$ less than 40 years of age) and therefore more likely to be involved in risk taking behaviour [3]. We observed an increase in the prevalence of RTA among older aged drivers. This may be related to increasing visual impairment with old age. 
Davidson in his examination of the interrelationship between British drivers' visual abilities, age and RTA histories found strongest positive association between RTA variables and visual disabilities, among older drivers [13]. As people age, visual functions deteriorate due to increase in the incidence of age-related ocular conditions such as cataract, macular degeneration, open-angle glaucoma, and diabetic retinopathy $[6,14,15]$. Thus there are 2 accident peaks in the life of an individual, in the young when one is prone to risk taking behaviour and in the elderly when visual impairment prevents adequate visual function. It is therefore important to target both groups in planning intervention programs for accident prevention.

The drivers engaged in part time jobs were more prone to RTA than those with no part time jobs. This is probably because they are over worked and don't have enough rest, and are therefore prone to RTA due to fatigue. Having part time jobs is related to the need to make enough money for their upkeep as well as the upkeep of their families. Adequate remuneration packages for services rendered to the institutions are therefore recommended as a way of preventing the seeking of part-time jobs that leads to fatigue related RTA.

A marginal reduction in the risk of RTA was observed amongst none users of social drugs such as kola nut, bitter kola, cigarette and alcohol. Alcohol depresses the central nervous system and therefore increases the response time of the user, making him less responsive to the challenges of driving particularly to coping with emergencies on the road [16]. It also causes dis-inhibition, impulsiveness and increased tendency to risk taking behaviour. A study which assessed illicit drugs and fitness to drive in Spanish medical driving test centres found a significant association between use of illicit drugs including alcohol and RTA / traffic infractions [17]. Kola nut and bitter cola contain $2.5 \%$ caffeine [4] which is a central nervous system stimulant just like nicotine in cigarette. These drugs are commonly used by drivers to avoid falling asleep, and often with out adequate rest before embarking on the trip. Many commercial drivers drive for hours without sleep and food, until fatigue inevitably sets in and a crash may be the end result [4].

\section{Conclusion}

Road traffic accidents were most commonly attributed to mechanical faults. Regular maintenance of official vehicles is therefore advocated and would ensure that they are kept in good condition. Use of drugs while driving should be discouraged among drivers to prevent RTA. Drivers should be discouraged from keeping part time jobs so as to ensure that they have adequate rest and are not over worked. Drivers should be relocated to administrative jobs or other sectors as the drivers begin to age. Drivers should have periodic eye tests to prevent accidents from visual impairment.

\section{Acknowledgments}

The authors are grateful to the management of the College of Medicine, University of Ibadan and the University College Hospital for giving permission for the study on their drivers.

\section{References}

1. Asogwa SE. Road traffic accidents: A major public health problem in Nigeria. Public Health. 1978; 92: 237-245.

2. Oyemade A. Epidemiology of road traffic accidents in Ibadan and its environs. Nigerian Medical Journal. 1973; 3:174177.

3. Asogwa SE. Some characteristics of drivers and riders involved in road traffic accidents in Nigeria. East African Medical Journal. 1980; 57:399-404.

4. Asogwa SE. Kola nut and road traffic accidents in Nigeria. American Journal of Public Health. 1978; 68:1228.

5. Humphries D. Three South African studies on the relation between road accidents and drivers' vision. Ophthalmic and Physiological Optics. 1987; 7:73-79.

6. Toczolowski J, Gerkowwicz M, Pracka A, Rycerz H. Vision defects in two age groups of drivers who caused road accidents. Klinika Oczna. 1996; 98:221224.

7. Szlyk JP, Seiple W, Viana M. Relative effects of age and compromised vision on driving performance. Human Factors. 1995; 37:430-436.

8. Nwosu SNN. Vision survey of Government motor vehicle drivers in Oyo State. A dissertation submitted to the National Postgraduate Medical College of Nigeria. May 1989. Pg vii.

9. Owsley C, Stalvey B, Wells J, Sloane ME. Older drivers and cataract: driving habits and crash risk. Journal of Gerontology. Series A, Biological Sciences and Medical Sciences. 1999; 54: 4:M 203-211.

10. Laberge-Nadeau C, Dionne G, Maag U, Desjardins D, Vanasse C, Ekoe JM. Medical conditions and the severity of commercial motor vehicle driver's road accidents. Accident Analysis and Prevention Journal. 1996; 28: 43-51.

11. Falola A. A survey of the visual status of Nigerian army drivers in Lagos. A 
Dissertation to the Faculty of Ophthalmology, National postgraduate Medical College of Nigeria. 2000; Pg xii.

12. Bener A, Ahmad MF, El-Tawil MS, AlBakre S. Visual impairment and motor vehicle accident. Middle East Journal of Emergency Medicine. 2004; 4: 1-9

13. Davidson PA. Inter-relationships between British drivers' visual abilities, age and road accident histories. Opthalmic and Physiological Optics. 1985; 5:195-204.

14. Klein R: Age related eye disease, visual impairment, and driving in the elderly. Human Factors. 1991; 33: 521-5.

15. West CG, Gildengorin G, HaegerstromPortnoy G, Lott LA, Schneck ME, Brabyn
JA. Vision and driving self-restriction in older adults. Journal of American Geriatric Society. 2003; 51: 1348-1355.

16. Lemoine $\mathrm{P}$, Ohayon $\mathrm{M}$. Abuse of psychotropic drugs during driving. Encephale. 1996; 22:1-6.

17. Carmen del Rio M, Alvarez FJ. Illicit drugs and fitness to drive: assessment in Spanish medical driving test centres. Drug Alcohol Dependence. 2001; 64:19-25. 